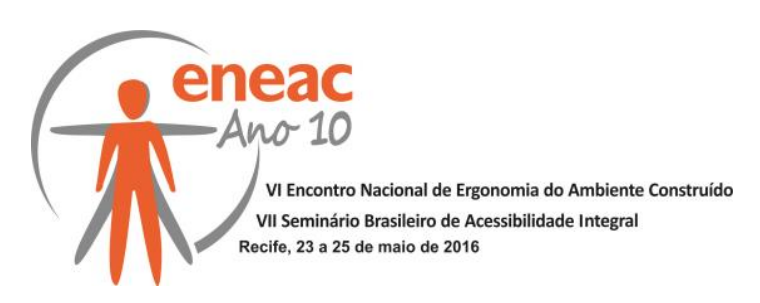

\title{
A QUALIDADE PERCEBIDA EM CENAS DO COMÉRCIO VAREJISTA DO CENTRO DE CARUARU
}

\author{
COSTA FILHO, Lourival (1); \\ OLIVEIRA, Isabela Fernandes (2); \\ YOKOYAMA, Sílvia Akemi (3) \\ (1) UFPE | Núcleo de Design | CAA | Doutor em Desenvolvimento Urbano \\ e-mail: lourivalcosta@yahoo.com \\ (2) UFPE | Núcleo de Design | CAA | Graduanda em Design \\ e-mail: isa.belafernandes@outlook.com.br \\ (3) UFPE | Núcleo de Design | CAA | Graduanda em Design \\ e-mail: silvia.yokoyama@hotmail.com
}

\begin{abstract}
RESUMO
A pesquisa apresentada buscou avaliar a qualidade percebida em cenas da paisagem midiática do comércio varejista do centro de Caruaru. A Teoria das Facetas foi adotada no desenho da investigação empírica, que utilizou o Sistema de Classificação Múltiplas para coletar os dados com consumidores e comerciantes locais. A técnica não métrica multidimensional Análise da Estrutura de Similaridade foi escolhida para interpretar os dados, que revelaram a aderência da coerência e da complexidade da paisagem midiática enfocada, para a avaliação da sua qualidade percebida, bem como o consenso das respostas entre os dois diferentes grupos abordados.
\end{abstract}

Palavras chave: qualidade percebida; imagem avaliativa de lugares; Teoria das Facetas.

\begin{abstract}
The research presented aims to evaluate the perceived quality of signscape scenes of retail outlets in the center of Caruaru. Facet Theory was adopted in the design of the empirical research, which used the Multiple Sorting Procedure to collect data from consumers and local traders. A multi-dimensional, non-metric procedure of Similarity Structure Analysis was chosen to interpret the data, which revealed the adherence to coherence and complexity in the evaluation of perceived quality, as shown in the consensus of responses of the two different groups interviewed.
\end{abstract}

Keywords: perceived quality; evaluative image of place; Facet Theory.

\section{INTRODUÇÃO}

De acordo com Villarouco (2011), são muitas as variáveis envolvidas na identificação da adequabilidade de um ambiente construído, o que torna complexa a tarefa de aferir tal adequação. A mesma autora ainda acrescenta que isso demanda esforços de diversas áreas envolvidas no processo de formatação do espaço edificado, incluindo as questões que tratam das sensações e percepções experimentadas pelo usuário na apropriação espacial. 


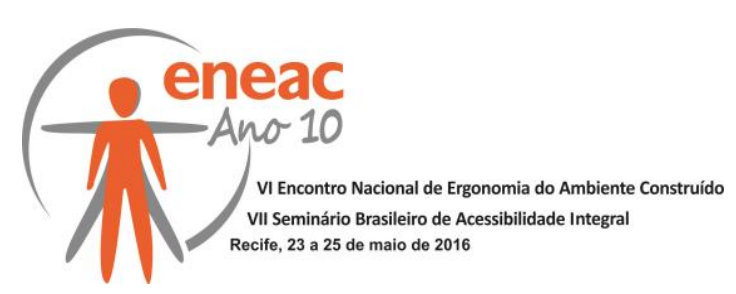

A pesquisa apresentada neste artigo envolve impressões cognitivas e sensoriais do público que utiliza regularmente o comércio varejista do centro da cidade de Caruaru, polo comercial estratégico do agreste pernambucano e Nordeste brasileiro, e adota a Teoria das Facetas como ferramenta auxiliar para a identificação dessas variáveis de caráter mais cognitivo, perceptual, dos dois grupos amostrais participantes (consumidores e comerciantes).

Como o comércio varejista normalmente ocorre ao longo dos principais eixos urbanos e são vistos regularmente por um grande número de cidadãos, seus principais leitores, tem um impacto substancial na imagem da cidade e na qualidade ambiental urbana.

Os eixos comerciais urbanos, sem dúvida, produzem sobrecarga visual, e o fator que mais contribui para isso é a paisagem midiática (multiplicidade de anúncios que o espectador pode apreender em uma única visualização). De acordo com Mendes (2004), na maior parte das vezes, as referências são negativas, centradas no congestionamento visual, dificuldade de orientação e de deslocamento nas ruas e calçadas, descaracterização de edifícios e obstrução visual de monumentos, embora não se possa esquecer que a imagem da cidade reflete a cultura da sua sociedade, e que dinamismo e vitalidade urbana se expressam, em parte, pelo congestionamento de pessoas, de veículos, de mercadorias e de imagens.

As políticas públicas das grandes cidades se preocupam com esse paradoxo da paisagem midiática, e usam várias técnicas para controlar a aparência desse tipo de paisagem, além da chamada "Lei da Publicidade", que dispõem sobre a veiculação de anúncios publicitários e sobre o ordenamento da publicidade no espaço urbano no âmbito municipal.

Tais diretrizes e Lei são, geralmente, definidas por especialistas e deixam para trás as análises empíricas sobre a qualidade visual percebida da paisagem midiática. Além disso, quase sempre são dadas por paradigmas estéticos, que costumam conter muito resquício de ideias ultrapassadas, inclusive preconceitos estéticos - hoje inadmissíveis - que pretendem fazer da cidade uma obra de arte (COSTA FILHO, 2012).

Isso significa que a aparência da paisagem midiática pode ser muito prejudicada se continuar sendo tratada como uma questão de gosto. Para evitar inadequações, é preciso tentar compreender os princípios subjacentes às respostas avaliativas do público usuário e transformá-los em orientações, para moldar o aspecto físico desse tipo de paisagem.

Logo, todo conjunto de regulamentações que recaísse na aparência da paisagem midiática deveria incluir no tratamento da questão um exame atento de como o público a vivencia, pois sua imagem pode afetar a experiência do observador e moldar o seu comportamento.

A partir do exposto, esta pesquisa tem como objetivo geral avaliar a qualidade percebida da paisagem midiática do comércio varejista do centro de Caruaru. Considerando a percepção de consumidores e comerciantes locais, elencam-se ainda como objetivos específicos: 1| verificar a aderência da coerência e da complexidade da paisagem midiática enfocada para a avaliação da sua qualidade percebida; 2| analisar o consenso entre esses dois grupos.

\section{QUESTÕES TEÓRICAS}

\subsection{A Qualidade Visual Percebida}

No que se refere à capacidade dos indivíduos de absorverem mensagens visuais, Vargas (2007) chama a atenção para as diferentes percepções e leituras da imagem ambiental, pois o excesso de mensagens pode passar despercebido sendo, muitas vezes, absorvido como um todo de informações, sem o interesse na identificação de suas partes. 


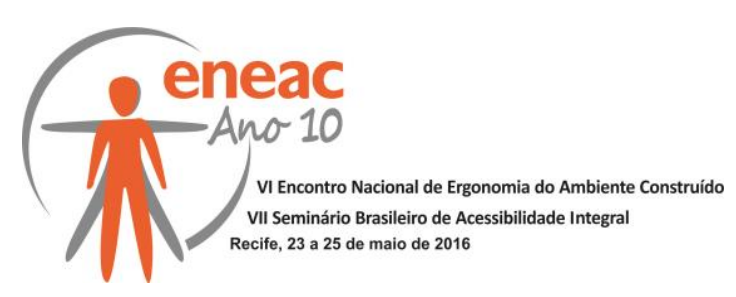

A qualidade visual percebida considera as experiências e as opiniões das pessoas com o ambiente, e não aquelas dos especialistas (NASAR, 1988), já que as imagens ambientais resultam de um processo bilateral e contínuo entre o observador e o ambiente.

Se os especialistas e as pessoas que experienciam regularmente um determinado ambiente compartilhassem valores estéticos, ou se os especialistas pudessem medir com precisão as necessidades estéticas das pessoas, a confiança na intuição profissional poderia ser aceita. Pesquisas, infelizmente, indicam que os especialistas diferem das pessoas comuns no assunto em suas preferências ambientais (GROAT, 1982; NASAR, 1988; NASAR, 1998).

Nessa perspectiva, a paisagem midiática enfocada terá uma resposta estética favorável ou qualidade visual, se um número significativo de pessoas que a experienciam regularmente, ao invés de especialistas, assim perceberem. Dessa forma, a qualidade visual da paisagem midiática será testada nesta pesquisa através dos julgamentos que os participantes expressarem para um conjunto de fotografias coloridas com cenas reais da área enfocada.

Duas características da paisagem midiática - complexidade e coerência - foram escolhidas para estudo, por causa da relevância delas para a Lei da Publicidade e de suas prováveis influências para a qualidade visual percebida. A complexidade é definida como a quantidade de variação na cena (diversidade); e a coerência como o grau em que a cena se encaixa.

A relevância dessas duas características para a Lei da Publicidade está no fato de essa poder controlar o formato e restringir a posição e a direção dos anúncios em relação às fachadas dos edifícios das lojas. Ao fazerem isso, controlam a complexidade. Apesar dessa Lei não controlar diretamente a coerência, controla uma variável relacionada, contraste, ou seja, o grau em que os anúncios se destacam ou contrastam com os demais elementos da cena. Assim, o aumento do contraste dos anúncios pode exagerar a redução da coerência.

A importância das características escolhidas para a qualidade visual percebida está no fato de essa construção, para Kaplan (1988), ser descrita como produto de duas necessidades humanas fundamentais: "estar envolvido" e "fazer sentido". O ambiente, então, deve ser envolvente para chamar a atenção humana e fazer sentido para se atuar/operar nele. A complexidade e a coerência desempenham relevante papel nessas necessidades humanas.

Por definição, pouca complexidade é monótona e fatigante; muita é caótica e estressante. $O$ nível médio de complexidade parece ser o mais agradável, ou mesmo o ideal. Dessa forma, a relação da complexidade com o tom hedônico (agradabilidade ou beleza) tem sido postulada como tendo a forma de 'U' invertido (BERLYNE, 1972; WOHLWILL, 1976).

A coerência é definida como o grau em que a cena se encaixa. Ajudando a compreensão e aumentando o valor estético, a coerência - obtida através da redução do contraste dos elementos na cena - pode reduzir a incerteza e aumentar o tom hedônico (WOLHWILL, 1976; KAPLAN, 1988).

A complexidade da paisagem midiática pode ser manipulada pela variação do formato, da localização e da direção dos anúncios nas cenas; já o contraste pode ser manipulado pela variação do tamanho e da cor (NASAR, 1988). Esses atributos físicos da paisagem midiática foram considerados para verificar a aderência da complexidade e da coerência da paisagem midiática enfocada para a avaliação da sua qualidade visual percebida.

A avaliação, presumivelmente, influencia o comportamento humano de tal forma, que as pessoas são mais propensas a visitar e permanecer em um lugar percebido favoravelmente e evitar outro percebido negativamente. Apesar das respostas avaliativas, por si só, não poderem prever o comportamento real, a avaliação combinada de respostas avaliativas e o comportamento previsto dá uma boa indicação do comportamento real (NASAR, 1988). Levando em conta essa afirmação, nesta pesquisa, os participantes foram solicitados a avaliar o grau em que várias cenas da paisagem midiática do comércio varejista do centro de Caruaru facilitam a sua intenção de visitar ou permanecer nesses lugares. 


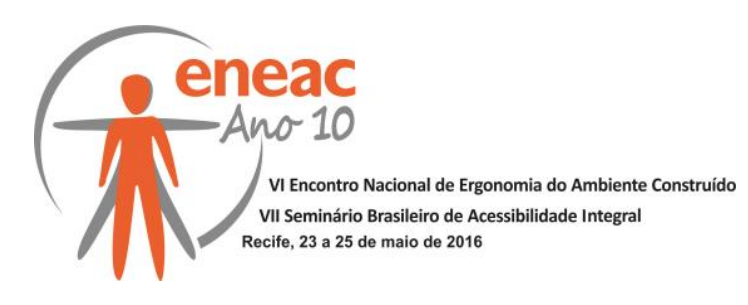

\section{QUESTÕES TEÓRICO-METODOLÓGICAS}

\subsection{Teoria das Facetas}

A Teoria das Facetas (TF) foi adotada no desenho da investigação empírica desta pesquisa (BILSKY, 2003; SHYE; ELIZUR; HOFFMAN, 1994). O uso da TF inicialmente envolve a identificação dos diferentes conceitos que delineiam a pesquisa, advindos da literatura ou de explorações in loco. Essa etapa consiste em estabelecer hipóteses, encontrar as facetas do modelo teórico e definir os elementos que as constituem. Cada faceta representa uma categoria conceitual, constituída por subcategorias de elementos a serem pesquisados.

Por definição, há três facetas básicas para avaliação de lugares, e cada uma representa um componente do lugar investigado: referente, foco, nível. A faceta do referente da experiência expõe os diferentes aspectos que as pessoas se baseiam para realizar suas avaliações. $A$ faceta do foco modula o referente da experiência. A faceta do nível evoca a existência da escala ambiental, que influi na avaliação de lugares. As relações entre os diversos aspectos da experiência das pessoas com o ambiente estão na sentença estruturadora, que descreve os componentes do ambiente e a forma como eles são experienciados pelos usuários.

\subsubsection{Aplicação da Teoria das Facetas na Pesquisa}

A Tabela 1 apresenta a sentença estruturadora, os nomes das facetas e seus elementos. Essa sentença é entendida aqui como uma declaração ou expressão para a avaliação da qualidade percebida de cenas da paisagem midiática do comércio varejista do centro de Caruaru. O primeiro tipo de faceta se refere aos sujeitos pesquisados (background). $O$ segundo abrange as variáveis pesquisadas (conteúdo). Esses dois tipos de facetas juntas determinam o campo de interesse da pesquisa (domínio). O terceiro se refere ao universo de respostas possíveis, normalmente apresentado em escala ordenada (racional comum).

\section{Tabela 1 - Sentença estruturadora para a avaliação da qualidade percebida de cenas da paisagem midiática do comércio varejista de Caruaru}

Em que medida a pessoa x (consumidor | comerciante) avalia que as cenas da paisagem midiática do comércio varejista do centro de Caruaru, com anúncios de

$\begin{array}{lllll}(\text { FACETA A) } & \text { (FACETA B) } & \text { (FACETA C) } & \text { (FACETA D) } \\ \text { COR } & \text { TAMANHO } & \text { LOCALIZAÇÃO } & \text { DIREÇÃO } \\ \text { (A1) suave } & \text { (B1) médio } & \text { (C1) média } & \text { (D1) paralela } & \text { facilitam } \\ \text { (A2) intensa } & \text { (B2) grande } & \text { (C2) alta } & \text { (D2) mista } & \end{array}$

RACIONAL COMUM
(1) nada;
(2) pouco;
(3) mais ou menos;
(4) muito;
(5) muitíssimo

sua intenção de visitar ou se prolongar nesses lugares?

(uma expressão da qualidade visual percebida na cena) 


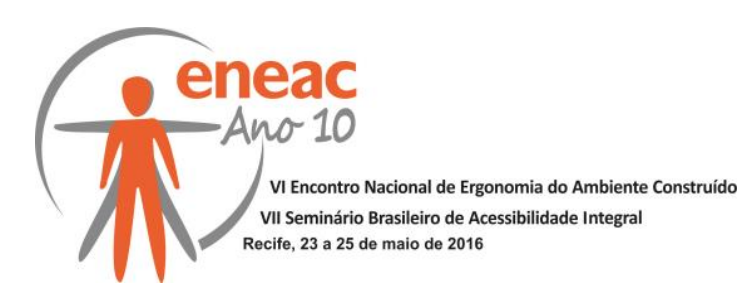

A população avaliada nesta pesquisa é constituída por participantes que, presumivelmente, têm diferentes interesses na paisagem midiática do comércio varejista do centro de Caruaru. Fazem parte desses diferentes grupos locais: 1| consumidores; 2| comerciantes.

A unidade espacial considerada para a investigação empírica desta pesquisa limitou-se aos principais eixos viários de comércio varejista, circunscritos ao centro de Caruaru, sem tomar nenhum deles mais especificamente.

Tendo os grupos amostrais e o recorte espacial definidos, o próximo passo é determinar as demais facetas e seus elementos internos, levando-se em conta os conceitos delineados. Para tal, foram consideradas apenas facetas do referente e desconsideradas facetas de foco e de nível, pois elas são invariáveis, ou seja, o foco da pesquisa é geral e o nível da experiência investigada é relativo a uma unidade espacial específica.

No sentido de verificar se os atributos relacionados com a coerência e a complexidade de cenas da paisagem midiática do comércio varejista do centro de Caruaru são determinantes para a avaliação da sua qualidade percebida, foram consideradas quatro facetas do referente - cor, tamanho, localização, direção - e desconsiderado o formato, pois todos são predominantemente quadrangulares na paisagem midiática enfocada. Entre as facetas consideradas, duas delas estão associadas à coerência das cenas (obtida através da redução do contraste): COR e TAMANHO. A faceta A define a saturação da COR dos anúncios nas cenas, podendo ser suave ou intensa. A faceta $B$ faz referência ao TAMANHO dos anúncios nas cenas, podendo ser médio ou grande. $O$ tamanho pequeno foi evitado, pois sua ocorrência é insignificante na paisagem enfocada. Os outros dois componentes estão coligados à complexidade das cenas. A faceta $\mathrm{C}$ diz respeito à LOCALIZAÇÃO dos anúncios nas fachadas das lojas, podendo estar posicionados numa altura média ou alta. $A$ faceta $D$ refere-se à DIREÇÃO que os anúncios assumem nas fachadas das lojas, podendo aparecer no sentido paralelo ou misto. A condição deles estarem perpendiculares ou destacados das fachadas é inexistente nas cenas da paisagem midiática recortada.

As combinações dos elementos internos das quatro facetas de conteúdo (A2xB2xC2xD2) possibilitam gerar 16 situações específicas ou diferentes, a serem avaliadas.

O próximo passo é informar o conjunto de categorias ou a amplitude de respostas possíveis de se obter dos participantes. Esse racional é comum a todas as facetas e, por conseguinte, à pergunta formulada na sentença estruturadora. Foi considerada uma escala de cinco intervalos: 1| nada; 2| pouco; 3| mais ou menos; 4| muito; 5| muitíssimo.

A sentença estruturadora (Tabela 1) atua como um mapeamento geral que liga todas as facetas (background, conteúdo, racional comum) e resulta em uma frase que norteia 0 projeto do instrumento de coleta de dados. Essa estrutura reflete a hipótese geral sobre as relações entre os elementos internos das facetas, sendo precisamente essas relações que serão testadas na situação empírica, para confirmar ou refutar essa estrutura. Logo, após a interpretação dos dados, há informações suficientes para construção ou não de uma nova sentença estruturadora como consequência direta dos resultados empíricos.

\section{QUESTÕES METODOLÓGICAS}

\subsection{Instrumento para Coleta de Dados}

Foi adotado o Sistema de Classificações Múltiplas (SCM) para levantar os dados, já que esse procedimento não depende inteiramente de declarações verbais, e ainda permite o uso de ilustrações e materiais visuais difíceis de serem acomodados em outros instrumentos. 


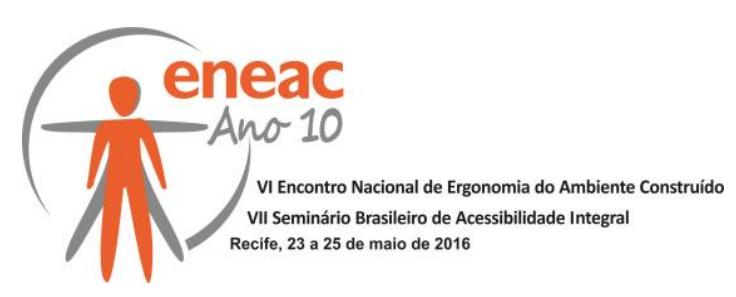

O SCM utiliza as classificações das pessoas para explorar seus sistemas conceituais. Essa técnica evoluiu da Grade de Repertório criada pelo psicólogo norte americano George Kelly, em 1955, que possibilitou examinar a natureza dos conceitos das pessoas ou seus construtos pessoais, basicamente vendo como elas atribuíam categorias a vários elementos.

O SCM consiste em pedir aos participantes para classificar os mesmos elementos diversas vezes. Os elementos apresentados devem ser agrupados pelas similaridades de modo tal, que elementos de uma mesma categoria tenham algo importante e distinto das demais. Esses elementos de estímulo dependem dos objetivos da pesquisa e podem ser gerados tanto pelo entrevistado, como pelo entrevistador. É possível ter grandes variações nos tipos de elementos classificados como atividades, objetos, imagens ou qualquer outra coisa.

A estrutura da investigação empírica realizada lançou mão de apenas uma classificação dirigida, ou seja, os participantes foram solicitados a fazer a classificação dos elementos de estímulo conforme um critério preestabelecido, com o objetivo de verificar se atributos associados à coerência e à complexidade da paisagem midiática do comércio varejista do centro de Caruaru seriam determinantes para a avaliação da sua qualidade percebida.

\subsubsection{Definição dos Elementos de Estímulo}

Nesta pesquisa, foram utilizadas fotografias coloridas com diferentes qualidades visuais da paisagem midiática do comércio varejista do centro de Caruaru como elementos de estímulo a serem apresentados aos entrevistados para classificações.

Esse conjunto de fotografias está diretamente associado às variáveis da pesquisa, listadas na sentença estruturadora para a avaliação da qualidade percebida de cenas da paisagem midiática do comércio varejista do centro de Caruaru (Tabela 1). O número de elementos de estímulo obtidos para as classificações, baseado no mapeamento dos elementos internos das facetas de conteúdo da referida estrutura, totalizou 16 diferentes situações ou cenas, que expressam o modo como os elementos que definem a investigação se relacionam. Foi considerado o tamanho $10 \times 15 \mathrm{~cm}$ para esse conjunto de imagens, manipuladas no programa computacional Adobe Photoshop, para eliminar postes e fios elétricos, na medida em que, de acordo com Nasar (1988), são co-variáveis da complexidade da cena e podem interferir negativamente na avaliação da preferência de lugares.

\subsection{Definição da População Amostral}

Finda a coleta dos dados, ao todo, foram entrevistados 80 sujeitos, sendo 52 consumidores e 28 comerciantes, donos de lojas do comércio varejista do centro de Caruaru. A diferença em relação à quantidade de sujeitos de cada grupo se deu em razão da dificuldade para se entrevistar comerciantes locais, muito inapetentes para participar de pesquisas acadêmicas, ainda que voltadas a assuntos de seu interesse.

Os procedimentos de classificações dirigidas foram realizados pessoalmente pelos pesquisadores e ocorreram principalmente nas residências dos consumidores, e nos locais de trabalho dos comerciantes. Os encontros foram agendados com antecedência, o que propiciou encontrar ambientes favoráveis, e todas as classificações foram devidamente registradas em um formulário especialmente desenvolvido.

No grupo dos consumidores, a maioria dos entrevistados é do sexo feminino $(53,84 \%)$, têm até 29 anos de idade $(71,15 \%)$ e ensino superior incompleto $(44,23 \%)$. Já no grupo dos comerciantes, a maioria deles também é do sexo feminino $(57,14 \%)$, têm até 29 anos de idade $(42,86 \%)$ e ensino médio completo $(53,57 \%)$. 


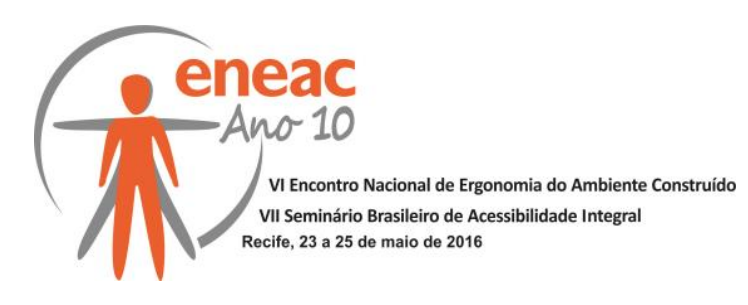

\subsection{Instrumento para Análise dos Dados (SSA)}

Os dados obtidos nas classificações dirigidas foram analisados por meio do procedimento não métrico e multidimensional SSA (Similarity Structure Analysis), executada com o auxílio do programa informático HUDAP (Hebrew University Data Analysis Program), desenvolvido por Reuven Amar e Shlomo Toledano, em 1994. O SSA, de acordo com Roazzi, Monteiro e Rullo (2009), é um sistema de escalonamento multidimensional concebido para analisar a matriz de correlações entre " $n$ " variáveis, representadas graficamente como pontos em um espaço euclidiano e fundamenta-se no princípio da contiguidade que, como tal, traduz as relações de similaridade entre os itens configurados pelas distâncias entre os pontos. As relações de similaridades podem formar regiões de contiguidade que possibilitam verificar se as hipóteses iniciais, fundamentadas na Teoria das Facetas, são transformadas em hipóteses regionais, em relação às quais se espera evidenciar regiões que correspondam aos elementos internos de cada faceta.

As facetas têm papel específico na estruturação do espaço multidimensional. Cada região é especificada para um determinado subconjunto de variáveis no espaço multidimensional, que as identifica através de um elemento interno comum pertencente a uma das facetas da sentença estruturadora. Essas regiões tomam formas de separação muito específicas, como faixas paralelas (axial), configurações circulares (modular), ou angulares (polar).

As análises das projeções geométricas a serem produzidas pela SSA para esta investigação irão revelar relações e regras implícitas aos dados obtidos, os quais seriam imperceptíveis nas análises quantitativas usuais.

Caso as hipóteses regionais se confirmem, são revelados aspectos relativamente estáveis do conceito que está sendo investigado, dando-lhes legitimidade, além de revelar a estrutura interna de conceitos e atributos, possibilitando a percepção de componentes empiricamente verificados e da forma como se inter-relacionam (SHYE; ELIZUR; HOFFMAN, 1994).

Por fim, para analisar a extensão do consenso dos grupos abordados, sobre a qualidade percebida das cenas da paisagem midiática do comércio varejista do centro de Caruaru, novamente se utiliza a técnica SSA, complementada por pontos na projeção base como variáveis externas, sem alterar o padrão original, um novo procedimento que permite examinar a relação empírica entre as variáveis escolhidas, neste caso, os dois grupos abordados nesta pesquisa, e a estrutura subjacente. Esse método é considerado um grande avanço da SSA e permite a integração de subpopulações no espaço do diagrama da SSA.

\section{QUESTÕES DE RESULTADOS}

\subsection{A Qualidade Percebida da Paisagem Midiática Investigada}

A questão explorada nas classificações dirigidas, que fez uso da SSA para interpretar os dados coletados, diz respeito ao interesse de consumidores e comerciantes de visitarem e permanecerem no comércio varejista do centro de Caruaru (expressão da qualidade visual percebida), identificado através de 16 cenas representadas em fotografias coloridas, com 0 objetivo de verificar se alguns atributos relacionados com a coerência e a complexidade da paisagem midiática enfocada na investigação são determinantes para a avaliação de sua qualidade visual percebida por esses dois diferentes grupos amostrais.

A matriz gerada pela SSA, representando os coeficientes de correlação entre as 16 cenas da paisagem midiática investigada e utilizadas para a avaliação de sua qualidade percebida, 


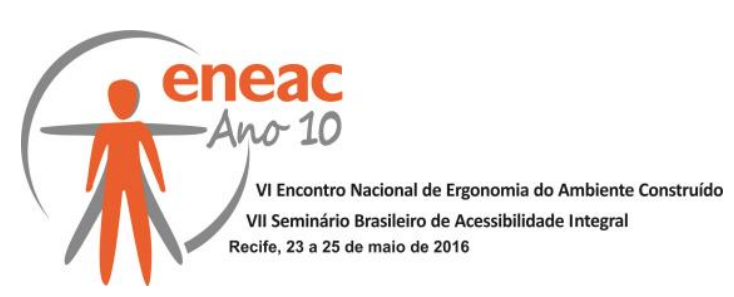

baseia-se nos escores atribuídos a cada uma dessas cenas pelos participantes dos dois grupos abordados nesta pesquisa, representados por 52 consumidores e 28 comerciantes.

Para testar cada faceta sobre o espaço do diagrama da SSA, as 16 fotografias receberam cores que identificam seu pertencimento a um dado elemento de composição interna da faceta. Em seguida, verificou-se a existência de padrões de contiguidade regional, ou seja, padrões reconhecíveis de divisão do diagrama em regiões formadas por fotografias de um mesmo elemento interno da faceta considerada.

Os resultados apresentados nos diagramas da SSA revelam que todas as quatro facetas testadas - cor, tamanho, localização, direção - formam estruturas regionais de contiguidade entre os itens similares de um mesmo elemento interno, confirmando a aderência de todos para a avaliação da qualidade visual percebida nas cenas da paisagem midiática do comércio varejista do centro de Caruaru, conforme previsto nas hipóteses iniciais.

Através dos diagramas das facetas A e B - COR, TAMANHO - nota-se que os grupos captaram essas duas categorias que formam regiões de similaridades. As Figuras 1 e 2 descrevem formas circulares que dividem os espaços dos dois diagramas em duas regiões distintas. O resultado merece atenção especial, pois esse padrão de divisão denota que tais categorias, associadas aqui ao contraste nas cenas da paisagem midiática do comércio varejista do centro de Caruaru, têm forte influência para a avaliação de sua qualidade percebida. As duas facetas do referente desempenham um papel modular nos espaços dos dois diagramas da SSA, um padrão em que os itens representados na parte central das formas circulares (cor intensa e tamanho médio) têm caráter mais geral e regulador para a avaliação sugerida do que aquelas da região periférica, que corresponde aos aspectos específicos da situação investigada. Isso significa que a cor intensa, e o tamanho médio dos anúncios nas cenas da paisagem midiática estudada facilitam mais a intenção de visitar e permanecer nesses lugares do que as demais com cor suave e tamanho grande, quando se considera a percepção dos dois diferentes grupos abordados, confirmando, em parte, a consistência conceitual de que a redução do contraste aumenta a coerência das cenas.

Figura 1 | Diagrama da Faceta COR [Dimensionalidade 3 - Eixo 1 versus Eixo 2] Partição regional para a faceta de referente. C.o. $A=0.17$

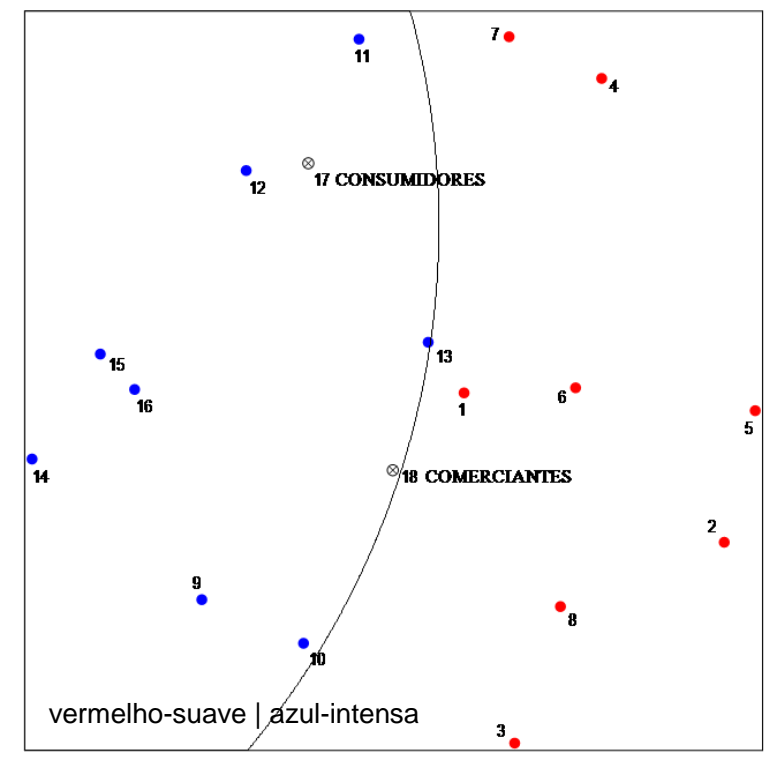

Fonte | Elaborado pelos autores com base na pesquisa realizada 


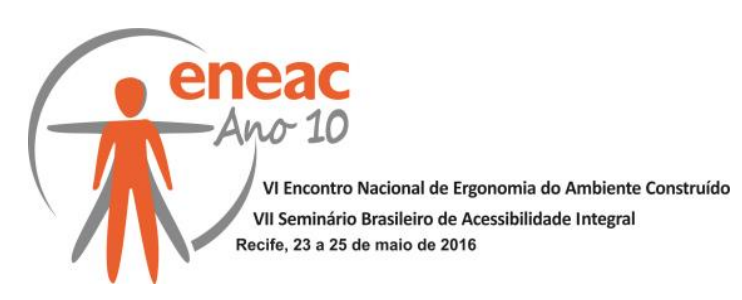

Figura 2 | Diagrama da Faceta TAMANHO [Dimensionalidade 3 - Eixo 1 versus Eixo 2] Partição regional para a faceta de referente. C.o.A $=0.17$

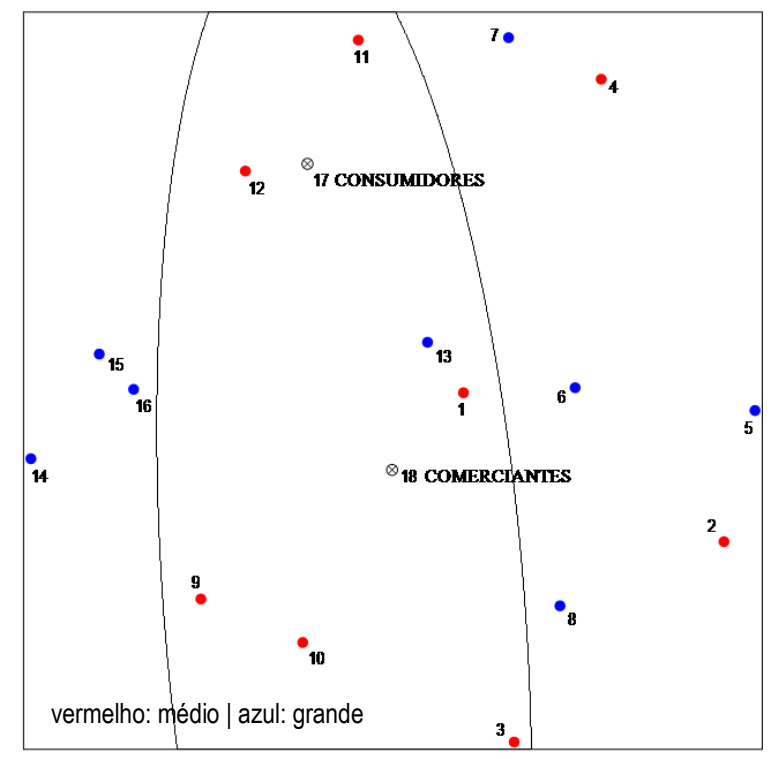

Fonte | Elaborado pelos autores com base na pesquisa realizada

Conforme evidenciado na Figura 1, consumidores e comerciantes estão localizados na área mais periférica do diagrama, na região de cor vibrante. Assim, em relação à avaliação da qualidade visual percebida nas cenas da paisagem midiática do comércio varejista do centro da cidade de Caruaru, ambos são mais influenciados pela cor vibrante dos anúncios, embora os comerciantes, na fronteira da outra região, também o sejam pelas cores suaves. Há, portanto, consenso entre os grupos para o atributo COR, e a cena que melhor prediz esse resultado, baseando-se nos escores obtidos nas classificações, é aquela de número 15 (Figura 3a). Já na Figura 2, nota-se que os grupos estão localizados na forma circular central, na região de tamanho médio. Ambos, portanto, são mais influenciados pelo tamanho médio dos anúncios. Há, de modo semelhante, consenso entre os grupos abordados para o atributo TAMANHO, e a cena de número 2 (Figura 4b) é aquela que melhor representa a qualidade percebida para esse atributo, na percepção dos dois grupos abordados.

Figura 3a | Qualidade Percebida (cor)

Figura 3b | Qualidade Percebida (tamanho)

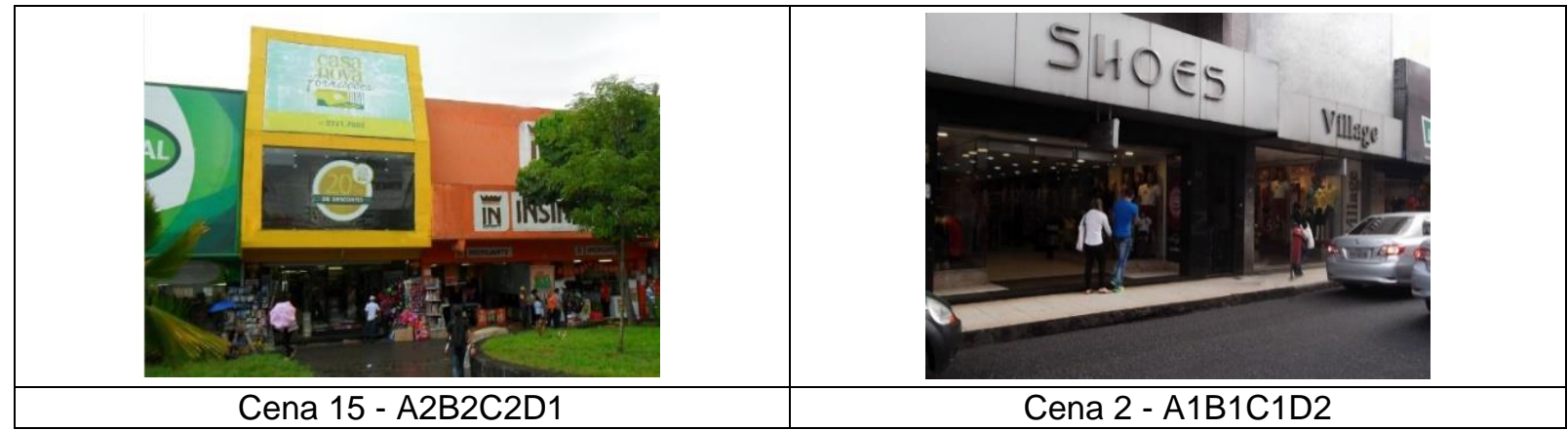

Fonte | Autores com base na pesquisa realizada 


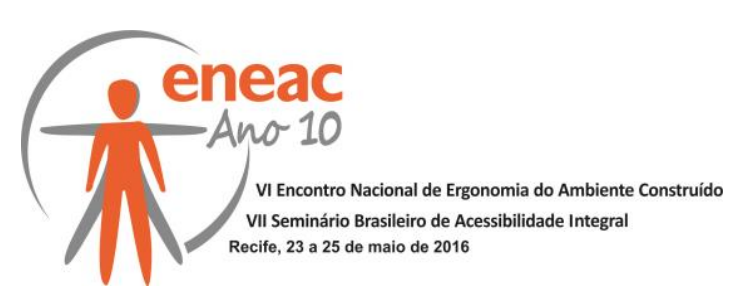

Explorando-se as Facetas C e D - LOCALIZAÇÃO, DIREÇÃO - percebe-se que os grupos captaram essas duas categorias que formam regiões de contiguidade. As Figuras 4 e 5 mostram formas circulares que dividem os espaços dos dois diagramas em duas regiões distintas. Tal padrão de divisão denota que as duas categorias, associadas à complexidade nas cenas da paisagem midiática, do comércio varejista do centro de Caruaru, têm forte influência para a avaliação aqui proposta, conforme previsto nas hipóteses iniciais desta pesquisa. Ambas as facetas desempenham um papel modular nos espaços dos diagramas da SSA, padrão em que os itens no centro das formas circulares (localização média e direção paralela) têm caráter mais geral e fundamental em relação às cenas das regiões periféricas. Isso significa que a localização média e a direção paralela, dos anúncios da paisagem midiática estudada, facilitam mais a intenção de visitar e permanecer nesses lugares do que as outras com localização alta e direção mista, segundo a percepção dos dois grupos, confirmando a consistência conceitual de que o nível médio de complexidade presumivelmente seria o ideal, ou seja, prediz a qualidade visual percebida nas cenas.

O grupo de consumidores, conforme a Figura 4, está posicionado na região de localização alta dos anúncios, enquanto o grupo de comerciantes na média. Isso significa que os consumidores são mais influenciados pela localização alta dos anúncios e os comerciantes pela localização média. A cena que melhor prediz esse resultado, pelos escores obtidos nas classificações, é a de número 2 (Figura 6a) para os primeiros, e a de número 15 (Figura 6b) para os segundos. Há, portanto, divergência entre os grupos para o atributo LOCALIZAÇÃO dos anúncios, nas cenas da paisagem midiática do comércio varejista do centro de Caruaru. Na Figura 5, o grupo de consumidores está situado na região de direção paralela dos anúncios, já o grupo de comerciantes na mista. Logo, em relação à avaliação das cenas, os consumidores são mais influenciados pela direção paralela dos anúncios nas cenas, e os comerciantes, pela direção mista. A cena que melhor prediz essa condição para os primeiros é a de número 15 (Figura $7 \mathrm{a}$ ), e para os segundos, a de número 2 (Figura $7 \mathrm{~b}$ ). Inexiste, portanto, consenso entre os grupos para o atributo DIREÇÃO.

Figura 4 | Diagrama da Faceta LOCALIZAÇÃO [Dimensionalidade 3. Eixo 1 versus Eixo 2] Partição regional para a faceta de referente. C.o.A $=0.17$

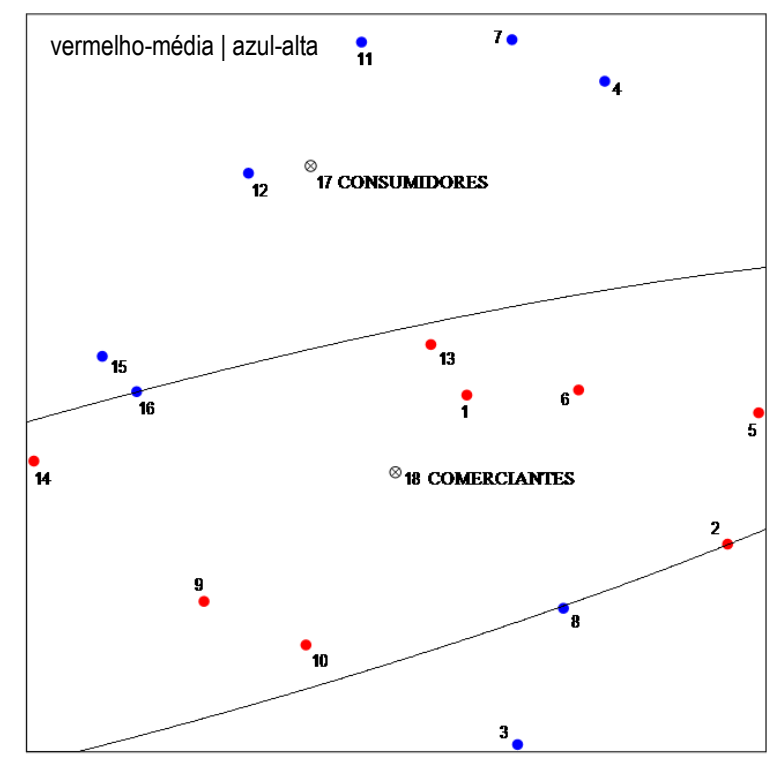

Fonte | Elaborada pelos autores com base na pesquisa realizada 


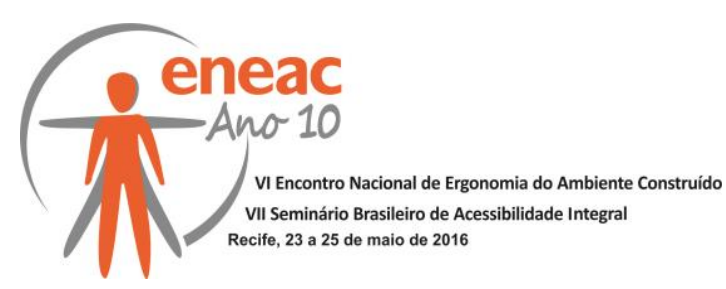

Figura 5 | Diagrama da Faceta DIREÇÃO [Dimensionalidade 3. Eixo 1 versus Eixo 2] Partição regional para a faceta de referente. C.o. $A=0.17$

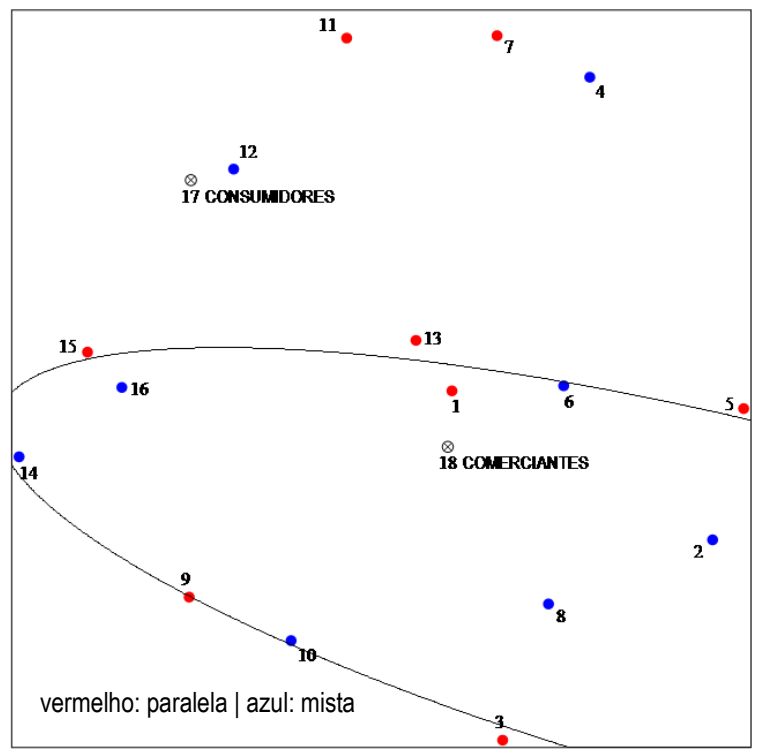

Fonte | Elaborada pelos autores com base na pesquisa realizada

Figura 6a | Qualidade Percebida (localização) Figura 6b | Qualidade Percebida (localização) por Consumidores por Comerciantes

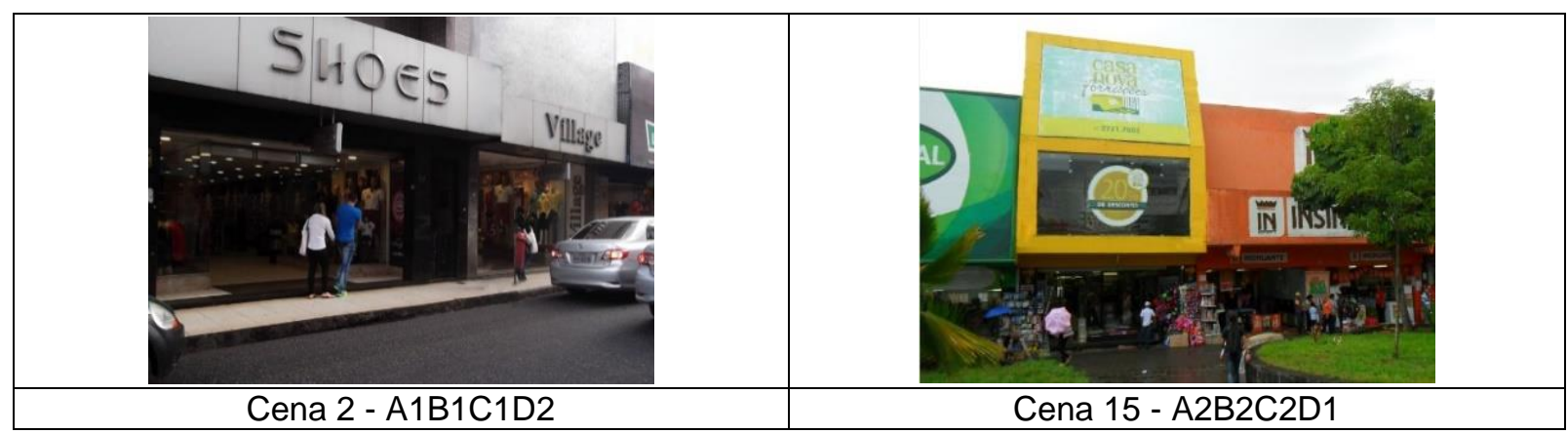

Fonte | Autores com base na pesquisa realizada

Figura 7a | Qualidade Percebida (direção) por Consumidores
Figura 7b | Qualidade Percebida (direção) por Comerciantes

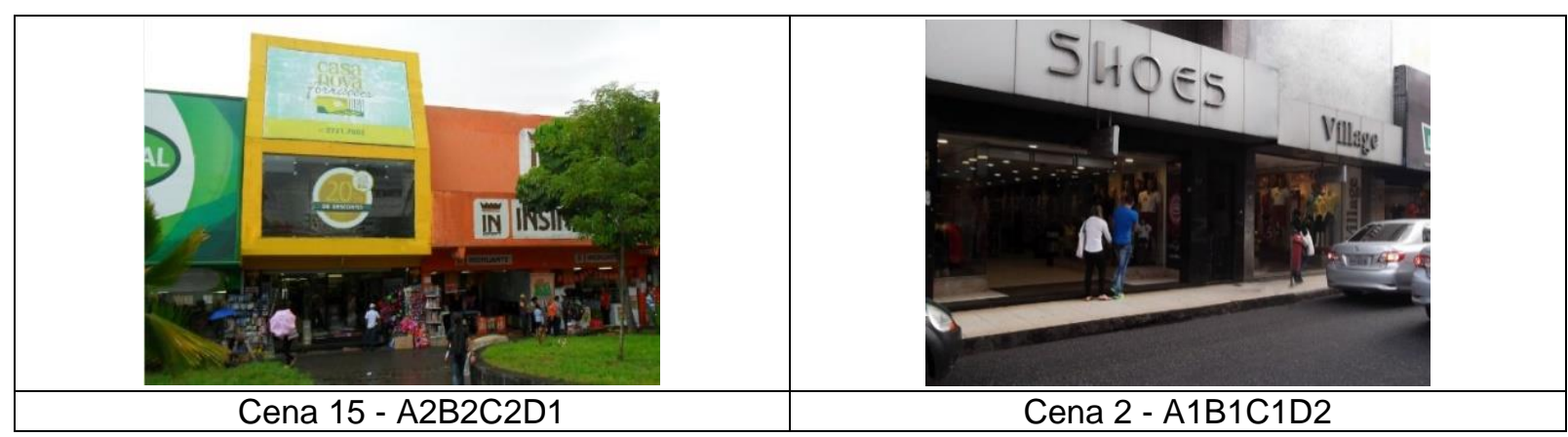

Fonte | Autores com base na pesquisa realizada 


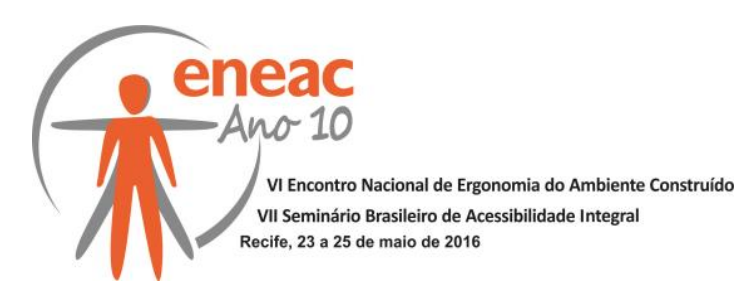

Buscando verificar a aderência da coerência e da complexidade da paisagem midiática, para a avaliação da sua qualidade percebida, apurou-se que os quatro atributos associados a essas duas características - cor, tamanho, localização, direção - demostraram ser consistentes, conforme previsto nas hipóteses iniciais desta pesquisa.

Ao analisar o consenso dos resultados entre os grupos abordados, foi apurado que há consenso para os atributos COR e TAMANHO dos anúncios nas cenas - cor intensa e tamanho médio -, mas divergência para os outros dois associados à complexidade.

Como consequência direta dos resultados empíricos, que confirmaram todas as hipóteses inicialmente formuladas, a sentença estruturadora geral para a avaliação da qualidade percebida da paisagem midiática do comércio varejista do centro da cidade de Caruaru foi confirmada em relação às categorias escolhidas e seus elementos de composição interna.

\section{REFERÊNCIAS BIBLIOGRÁFICAS}

BERLYNE, Daniel E. (1972). Ends and meanings of experimental aesthetics. Canadian Journal of Psychology, 26, 303-325.

BILSKY, Wolfgang. A Teoria das Facetas: noções básicas. In Estudos de Psicologia, v.8, n.3, 2003. p. $357-365$

GROAT, Linda. Meaning in Post-Modern architecture. An examination using the multiple sorting task. In Journal of Environmental Psychology, v. 2, n. 1, March 1982, p. 3-22.

KAPLAN, Stephen. Perception and landscape: conceptions and misconceptions. In NASAR, Jack. (Ed.). Environmental Aesthetics: theory, research, and application. New York: Cambridge University Press, 1988. p. 45-55.

COSTA FILHO, Lourival Lopes. MIDIÁPOLIS: comunicação, persuasão e sedução da paisagem urbana midiática. 2012. 271f. Tese (Doutorado) - Universidade Federal de Pernambuco, Curso de Pós-Graduação em Desenvolvimento Urbano.

MENDES, Camila Faccione. Interferência da Mídia Exterior na Paisagem Urbana. 2004. 211p. Dissertação (Mestrado em Arquitetura e Urbanismo). FAUUSP, São Paulo, 2004.

NASAR, Jack. Environments Aesthetics: theory, research, and applications. New York: Cambridge University Press, 1988.

NASAR, Jack. The Evaluative Image of the City. London: SAGE, 1998.

ROAZZI, Antonio; MONTEIRO, Circe Maria Gama; RULLO, Giuseppina. Residencial satisfaction and place attachment: A cross-cultural investigation. In COHEN, Arie (Ed). Facet Theory and Scaling: In search of structure in behavioral and social sciences. Israel: Rubin R. I. D, 2009.

SHYE, Samuel; ELIZUR, Dov; HOFFMAN, Michel. Introduction to Facet Theory: Content design and intrinsic data analysis in behavioral research. London: Sage, 1994.

VARGAS, Heliana Comin. Limites ao controle da publicidade na paisagem urbana. In: Revista on line, Ambiente Já, 2007.

VILLAROUCO, Vilma. Tratando de ambientes ergonomicamente adequados: seriam ergoambientes? In MONT'ALVÃ̃, Cláudia; VILLAROUCO, Vilma. (Orgs.). Um novo olhar sobre o projeto: a ergonomia no ambiente construído. Teresópolis: 2AB, 2011.

WOHLWILL, Joachim F. Amount of stimulus exploration and preference as differential functions of stimulus complexity. In Perception \& Psychophysics, Santa Barbara, v. 4, n. 5, 1968, p. 307-312. 